\title{
O "ASSUNTO" COMO ELEMENTO DE CLASSIFICAÇÃO PARA DOCUMENTOS DE ARQUIVO NO INICÍO DO SÉCULO XX E SUAS INFLUÊNCIAS EM ABORDAGENS CONTEMPORÂNEAS
}

\author{
THE "SUBJECT" AS ELEMENT OF RECORDS \\ CLASSIFICATION IN THE EARLY XX CENTURY AND \\ ITS INFLUENCES ON CONTEMPORARY APPROACHES
}

\author{
Paulo José Viana de Alencara \\ Clarissa Moreira dos Santos Schmidtb
}

\begin{abstract}
RESUMO
Introdução: Apesar das especificidades inerentes aos documentos de arquivo, encontramos discussões e práticas favoráveis à classificação destes documentos ser fundamentada no "assunto". Nesse sentido, é possível refletirmos sobre tal abordagem classificatória a partir de uma amostragem que consiste em dois instrumentos de classificação do começo do século XX de órgãos públicos dos Estados Unidos e do México, bem como expormos as bases históricas de parte do desenvolvimento dessa perspectiva no Brasil. Objetivos: Primeiramente destaca-se a importância de estudos sobre a história da Arquivologia dentro de uma abordagem internacional e comparativa. Posto isso, busca-se explicitar discussões sobre a classificação de documentos de arquivo, seus objetivos e métodos, além de analisar os referidos instrumentos segundo seus elementos de elaboração, correlacionando-os a algumas questões suscitadas no debate atual sobre classificação em arquivos. Metodologia: Para alcançar tais objetivos, valemo-nos de uma revisão e sistematização de literatura nacional e internacional em perspectiva histórica, que abrangeu o período de 1912 até 2018. Resultados: Os resultados sugerem uma histórica percepção da necessidade de reformulação metodológica para a construção de instrumentos de classificação com ênfase na identificação do contexto de produção dos documentos de arquivo. Conclusões: Foi possível concluir que, apesar desta percepção, a efetiva difusão de metodologias de classificação adequadas para os documentos de arquivo, incluindo o Brasil, vai de encontro a um processo histórico não só de aderência, mas, sobretudo de institucionalização da classificação baseada em assuntos.
\end{abstract}

\footnotetext{
a Mestrando do Programa de Pós-graduação em Ciência da Informação da Universidade Federal Fluminense (UFF). Bacharel em Arquivologia pela Universidade Federal Fluminense (UFF). Email: alencarpauloj@outlook.com

b Doutora em Ciência da Informação pela Universidade de São Paulo (USP). Docente do Programa de Pós-Graduação em Ciência da Informação da Universidade Federal Fluminense (UFF). Email: clarissaschmidt@id.uff.br
} 
Descritores: Arquivologia. Arquivos públicos. Classificação. Plano de classificação de documentos.

\section{INTRODUÇÃO}

Uma das características nucleares do documento de arquivo é o fato de ser produzido, recebido e acumulado por registrar ações dentro de um contexto jurídico e administrativo. Deste modo, sua classificação, isto é, o conjunto de operações de natureza intelectual que identifica seu contexto de produção, deve se concentrar, fundamentalmente, na identificação da ação contida nos documentos de arquivo.

Ao passo em que o reconhecimento deste contexto de produção favorece a execução de outras fases do processamento técnico dos documentos de arquivo, reverbera na literatura da área a sugestão de uma lacuna de discussões sobre os aspectos metodológicos da classificação.

Um destes aspectos é compreender o porquê da utilização do método de classificação baseada em assuntos, apropriada da Biblioteconomia, aos documentos de arquivo, cujas razões de produção e custódia delineiam uma natureza teórica única e distinta do documento tratado pela Biblioteconomia. Deste modo, uma aproximação histórica e reflexiva sobre o tema se faz necessária. Assim, este artigo se apresenta como uma pesquisa de natureza qualitativa e exploratória, operacionalizada através de revisão e sistematização de literatura que abrange o período de 1912 até 2018, na qual se apresentam e analisam planos de classificação de órgãos públicos dos EUA e México do início do século $X X$, além de apontar marcos de aderência à classificação baseada em assuntos no Brasil.

\section{DEMARCANDO O ESCOPO: A RELEVÂNCIA DE ESTUDOS HISTÓRICOS SOBRE A TRAJETÓRIA DA ARQUIVOLOGIA EM PERSPECTIVA INTERNACIONAL}

A Arquivologia enquanto ciência tem apresentado uma dinâmica percepção sobre sua relação (e de seu objeto) com a sociedade e com outros 
campos do conhecimento, entretanto, observou Craig (1992, p. 113, tradução nossa), existe um "breve olhar para dentro, para nossa própria história e nossas próprias raízes", isto é, não se têm pesquisado tanto sobre a história das relações entre seu fazer e saber na mesma proporção.

Terry Cook, por sua vez, também identificou a incipiência nesta seara de pesquisa e a situa "na ponte entre teoria e prática, isto é, através do abismo entre os princípios guiadores, ideias e sua verdadeira implementação em instituições arquivísticas" (1997, p. 19, tradução nossa).

Ainda de acordo com Craig (1992, p. 118), o que motiva pesquisas acerca da história da Arquivologia em um cenário de inúmeros desafios sobre a "prática", ou ainda sobre o "fazer", são três matrizes, dentre as quais destacamos duas.

A primeira se justifica a partir da visualização de uma noção de contexto sobre os profissionais e seu objeto, assim, o exercício das funções arquivísticas se dá de forma mais fundamentada.

A segunda propõe, dado seu nascimento enquanto fazer, e a persistência mais ou menos dicotômica entre profissionais "práticos" e "teóricos", de acordo com a autora, uma história da Arquivologia aproximaria esses profissionais e seria basilar para uma identidade profissional única (CRAIG, 1992, p. 118 tradução nossa).

No prisma prático, se a universidade é um dos lugares privilegiados de construção do pensamento arquivístico em termos científicos, limitar nossa capacidade de abstração sobre nossos objetos e práticas em um mesmo universo discursivo iria opor-se a tal estatuto (DEVRIESE, 2007, p. 2). Nesse sentido, uma análise contextualizada dos mesmos através do tempo pode produzir uma percepção sistemática, não somente sobre problemas rotineiros do trabalho arquivístico, mas sobretudo acerca dos entendimentos e delimitações conceituais na nossa área.

Já acerca da questão da identidade profissional, para além do reforço de uma imagem perante a sociedade, segundo a espanhola Antonia Heredia Herrera (2012), há nesse contexto o debate sobre a transformação de conceitos na Arquivologia ante a necessidade de compreender a produção, uso e gestão 
de documentos - GD, influenciados pelo instrumental da tecnologia da informação.

Ainda de acordo com a autora, é tempo de repensarmos sistematicamente a ciência dos arquivos, principalmente no que se refere ao uso e definições de nossos termos. Heredia Herrera (2012, p. 1-4) identifica uma larga expansão de termos em nossa teoria e prática que outrora já foram fundamentados, onde tal efeito pode ser harmonizado através de uma revisitação aos mesmos.

Uma forma de atuação face a tais problemáticas contemporâneas da Arquivologia é o estudo comparativo através de bases históricas, que para Richard J. Cox (1988, p. 141), é algo capaz de investigar causas e padrões de sucessos e falhas na gestão de instituições e serviços arquivísticos.

Nessa linha de pensamento, uma abordagem que privilegia esta análise é a perspectiva internacional. Em uma discussão ao redor de qual seria a melhor formação profissional arquivística, isto é, em escolas de treinamento ou através do ensino universitário, Joseph Cuvellier (1912, p. 301-302), no Congresso Internacional de Arquivistas e Bibliotecários realizado em Bruxelas em 1910, por exemplo, já sugeria a importância de uma abordagem internacional à problemática para indicar que uma maneira de construir a educação arquivística para cada país poderia ser a observação da formação profissional em outros países.

Posteriormente, no epicentro do surgimento da "Arquivística Integrada", influenciada principalmente pelos canadenses Carol Couture, Jean-Yves Rousseau e Louise Gagnon-Arguin, o brasileiro Luís Carlos Lopes (1997-1998) identificou a inserção da Arquivologia na "Era da Informação" (1997-1998, p. 45) e se baseou em Marcel Lajeunesse para uma visão mais abrangente de uma compreensão internacional como vital para o exercício dos "profissionais documentários".

Nessa direção, Lopes (1997-1998, p. 49) salienta que a Arquivologia produziu construções teóricas aplicáveis a todos os países, como o princípio de respeito aos fundos, entretanto, também coexistem aspectos conceituais com percepções adversas ao longo de diferentes realidades arquivísticas.

Nesta mesma linha de argumentação, pontuou o ex-presidente da Society 
of American Archivists (SAA), Thomas Hickerson (2001, p. 9), que restringir nossas técnicas de tratamento dos documentos de arquivo entre fronteiras geográficas é prejudicial para uma visão mais ampla do nosso objeto de estudo, pois o "mandato arquivístico" é internacional e todos os documentos de arquivo identificados como tal corroboram para a apreciação da complexidade no relacionamento entre documentos de arquivo, sociedades e organizações.

O arquivista holandês Ketelaar (1997, p. 144-145) também analisa a situação e ressalta a importância desse ponto de vista destacando as diferenças culturais e terminológicas em uma abordagem internacional na pesquisa arquivística. Desse modo, para o autor é necessário que

\begin{abstract}
Antes que possamos decidir pela "uniformidade", antes de podermos codificar teorias e princípios globais e antes de podermos proporcionar a construção e implementação universal de modelos aplicáveis nós temos que estudar as diferenças. (KETELAAR, 1997, p. 146-147, tradução nossa).
\end{abstract}

Ainda como pontua o arquivista holandês, o cenário para a Arquivologia é desafiador, e descrever cada "domínio local" do seu conhecimento antes de estipular modelos universais é um aspecto que deve constituir a pesquisa na área. O autor vislumbra como ferramenta para tal, uma análise comparativa através de "culturas, sociedades e também do passado" (KETELAAR, 1997, p. 147, tradução nossa).

Tratando-se de classificação em arquivos, a proposta de Ketelaar sugere inúmeras possibilidades de pesquisa, como por exemplo, a compreensão da classificação de documentos de arquivo em diferentes países, quando esta não se baseava em princípios e metodologias constituintes da teorização arquivística, identificando os resultados esperados e alcançados por esses princípios e metodologias não arquivísticos.

\title{
3 DISCUSSÕES CONTEMPORÂNEAS SOBRE CLASSIFICAÇÃO NA ARQUIVOLOGIA
}

Atualmente, as discussões em torno da classificação ocupam um lugar nas pesquisas e práticas arquivísticas de acordo com autores como: Orr (2005); Foscarini (2009); Henttonen e Kettunen (2011); Mokhtar e Yusof (2015a, 2015b, 
2016); Mokhtar et al. (2016); Caravaca (2017) e Guercio (2017).

A partir do diálogo com os autores supracitados, pretendemos apresentar um panorama geral do debate sobre a classificação de documentos de arquivo na Arquivologia, considerando os riscos do resumo de tais questões e, ainda que não seja uma análise total da literatura disponível, mas sim, um recorte sobre as principais questões sobre o assunto do ponto de vista destes autores.

Nosso objetivo aqui é principalmente identificar se a discussão histórica e metodológico-comparativa sobre esta função arquivística se demonstra útil, o que podemos projetar hoje a partir dessa ótica, e como benefício secundário propor a discussão sobre uma literatura pouco citada e discutida no Brasil.

O arquivista inglês Stuart Orr (2005, p. 37-75) identifica a preferência na literatura científica, em entrevista aos profissionais atuantes na GD, pela classificação baseada em funções e na criação de modelos para tal, ainda que o método não construa "caixas" para os documentos (ORR, 2005, p. 112). Afirma também que ocorre uma dificuldade na elaboração de planos de classificação através da metodologia funcional (ORR, 2005, p. 11). Por fim, concorda com a proposta de Shepherd e Yeo; de uma "classificação virtual" baseada em metadados como uma alternativa (ORR, 2005, p. 120-121).

Posteriormente, a arquivista italiana Fiorella Foscarini (2009) realizaria uma das pesquisas de maior fôlego sobre a temática. A autora faz uma extensa revisão de literatura, destacando a sobreposição da contextualização propiciada através do vínculo arquivístico na classificação, explícita no plano de classificação, em contraposição a sua função de recuperação da informação (FOSCARINI, 2009, p. 3). A conclusão de Foscarini (2009, p. 281-282) é que as culturas organizacionais devem ser também de objeto de estudos para a criação de planos de classificação eficientes e inteligíveis.

Exatamente sob tal prisma, os finlandeses Henttonen e Kettunen (2011) direcionam suas pesquisas, examinando como diferentes grupos hierárquicos em um órgão público da Finlândia lidam com o plano de classificação inserido em um software de gestão de documentos de arquivos digitais. De uma forma geral, a maior parte dos funcionários maneja poucas classes e tem pouca dificuldade com tal, o que demonstra a necessidade de uma divisão do trabalho 
rígida. Entretanto, o fato do Eletronic Records Management System -ERMS não capturar as comunicações internas por e-mail, por exemplo, sugere que uma quantidade significativa de documentos de arquivo não são classificados, armazenados e avaliados corretamente (HENTTONEN; KETTUNEN, 2011, p. 99-100).

Entre os anos de 2015 e 2016, pesquisadoras malaias da University Kebangsaan realizaram diversos estudos para compreender os conceitos e efeitos da classificação, bem como modelos e requisitos para a mesma, em um horizonte que privilegia a gestão de documentos na acepção segregacionista norte-americana do trabalho arquivístico; a realidade de produção de documentos de arquivo em meios digitais e as iniciativas de governo eletrônico (MOKHTAR; YUSOF, 2015a, 2015b, 2016); (MOKHTAR et al, 2016).

Os três principais resultados obtidos nesses estudos consideram: a) uma proximidade nos conceitos de classificação entre Biblioteconomia, Ciência da Informação, Tecnologia da Informação e Arquivologia, os dois primeiros agindo principalmente sobre a recuperação da informação e os dois últimos agindo para a contextualização e garantia de autenticidade dos documentos de arquivo nos sistemas digitais. Nesse sentido, as autoras identificam a falta de um modelo holístico (MOKHTAR; YUSOF, 2015a, p. 181).

Posteriormente: b) a transformação histórica da metodologia de classificação funcional do modelo função-atividade para função-atividade-ação, algo que reforça sua posição como método mais adequado para a classificação de documentos de arquivo; além de uma percepção dos profissionais da área em relação a proximidade entre os conceitos de classificação entre a Arquivologia, Biblioteconomia, Ciência da Informação e Tecnologia da Informação (MOKHTAR; YUSOF, 2015b, p. 407).

Plasmada na realidade digital: c) os modelos de classificação demonstram pouca clareza instrumental e um caráter demasiado conceitual que talvez justifique sua pouca ou inadequada aplicação ante sistemas de informação genéricos não modelados a partir dos requisitos arquivísticos para a GD (MOKHTAR; YUSOF, 2016, p. 1273), sendo apresentada uma sugestão de modelo conceitual de classificação funcional para documentos eletrônicos 
(MOKHTAR et al, 2016).

As arquivistas italianas Maria Mata Caravaca (2017) e Maria Guercio (2017) se dispõem a analisar respectivamente: os elementos e relacionamentos contidos nos planos de classificação e o papel da classificação de documentos de arquivo nos sistemas documentários digitais ${ }^{1}$.Caravaca (2017, p. 19) aponta a diferença existente no contexto italiano do plano de classificação (piano di classificazione) e plano de arquivamento (piano di fascicolazione) e destaca ainda a falta de pacificação na literatura da área sobre os elementos da classificação funcional, isto é: competência, função, atividade/processo e ação. Caravaca (2017, p. 30) pontua, por fim, que apesar de pouco inteligível para os produtores, o plano de classificação desempenha um papel fundamental em conjuntos orgânicos produzidos em ambientes digitais se torna ainda mais necessário para evidenciar o contexto.

Guercio (2017) por sua vez não identifica um lugar privilegiado para a classificação na pesquisa e prática arquivística contemporânea, ressalta a necessidade de estudos teóricos e sobre cultura organizacional, e ainda, atribui o relativo sucesso da experiência italiana na gestão de documentos em ambiente digital a larga tradição arquivística e de registro de seu país, por fim, defendendo uma ampliação da normatização da gestão em âmbito internacional.

Como a nossa breve análise sobre a atual literatura sobre classificação pode demonstrar, o papel desta função arquivística de maneira geral e os principais pontos de encontro dos autores foram: a) a classificação tem sido largamente projetada considerando o contexto digital de produção e armazenamento de documentos de arquivo digitais, o que reforça a dimensão aplicada da Arquivologia enquanto integrante do grupo de ciências sociais aplicadas e b) a metodologia funcional é amplamente aceita como mais adequada.

Ainda sobre seu papel, permanece sendo destacado: o de contextualizar a produção documental, fazer explícito o vínculo arquivístico e a organicidade através do plano de classificação, além da recuperação da informação.

\footnotetext{
1 Tradução nossa. A palavra na língua original é sistemi documentari digitali.
} 
Todavia, a relevância de um ponto de vista sobre o outro é uma divergência significativa. Alguns enfatizam a predominância da contextualização em detrimento da recuperação da informação, como: Foscarini (2009); Henttonen e Kettunen (2011); Caravaca (2017) e Guercio (2017). Não enfatiza uma relevância de um sobre o outro diretamente: Orr (2005). Tendem a projetar a recuperação da informação em função da contextualização: Mokhtar e Yusof (2015a; 2015b; 2016); Mokhtar e outros (2016).

O desejo por um modelo holístico que integre as perspectivas é apontado por Mokhtar e outros (2016), e a cultura organizacional é levada em conta em todas as pesquisas, sendo que as nuances desta para a classificação são especialmente visíveis se considerarmos o contexto italiano (CARAVACA, 2017); (GUERCIO, 2017), finlandês (HENTTONEN; KETTUNEN, 2011) e malaio (MOKHTAR; YUSOF, 2015a, 2015b, 2016).

Dessa forma, entendemos que a análise de temáticas arquivísticas em uma abordagem internacional continua útil para contextualizar a aplicabilidade de conceitos e metodologias. Além disso, demonstra a heterogeneidade de pontos de vista em nossa área.

A dimensão histórica é especialmente útil nesse momento se constatarmos que: a) ocorre, como vimos, uma tendência globalizante em busca de modelos universais e b) uma visão que sugere uma sobreposição do papel para recuperação da informação na classificação de documentos de arquivo.

Modelos universais, como nos indicaram Lopes (1997-1998) e Ketelaar (1997), pressupõem o conhecimento das diferenças. Assim, para a classificação de documentos de arquivo, a perspectiva internacional e histórico-comparativa é um recurso ilustrativo e referencial das características das práticas arquivísticas quando estas não estão circunscritas junto a um construto teórico, metodológico e conceitual próprio, nos servindo de base para aferições contemporâneas.

Dito isto, nos cabe agora contextualizar, de maneira geral, a criação da classificação decimal por assuntos no âmbito da Biblioteconomia e refletir sobre seu uso em documentos de arquivo. 


\section{DIFUSÃO DA CLASSIFICAÇÃO DECIMAL POR ASSUNTOS PARA DOCUMENTOS DE ARQUIVO}

No momento do estabelecimento do governo dos Estados Unidos, ao longo do século XVIII, adotou-se um sistema de registro nos órgãos integrantes da Administração Pública que não incluía a classificação dos documentos, entretanto, estabelecia de forma rudimentar o arquivamento da correspondência: a) recebida, b) expedida (que eram copiadas em um livro e posteriormente através de papel carbono) e c) uma categoria de miscelânea. A ordenação interna dessas grandes classes seguia a ordem alfabética. Tal sistema foi utilizado até o fim do século XIX (CHATFIELD, 1950, p. 261).

A esta época, no âmbito das bibliotecas, Nathaniel B. Shurtleff publica em 1856 A Decimal System for the Arrangement and Administration of Libraries. Porém, apesar de usar a notação decimal antes de Melvil Dewey, estabelecia a numeração das estantes como parâmetro de organização. Tal ideia de localização fixa, contudo, não resolveu o problema de localização dos livros nas bibliotecas (DEUTRICH, 1965, p.199-200).

Melvil Dewey, mais tarde, trabalhando em tempo parcial na biblioteca do Amherst College visualizou este problema e propôs, em 1873, uma classificação do conhecimento humano em dez classes principais (DEUTRICH, 1965, p. 200) que se subdividiriam sucessivamente em casas decimais. A proposta foi aceita e publicada em 1876 (DEUTRICH, 1965, p. 201).

Um dos aspectos que favoreceu a difusão da metodologia foi a sua adoção pelo Instituto Bibliográfico Internacional. Já no campo dos arquivos, para a Administração Pública foi a criação do móvel de arquivo horizontal em 1892 que estimulou a criação de sistemas de arquivamento (DEUTRICH, 1965, p. 201). Todavia, a disseminação de adaptações do método de Dewey para a classificação de documentos de arquivo na Administração Pública americana também foi largamente influenciada pela realidade privada.

Em 1898, o presidente da empresa férrea Baltimore and Ohio Railroad solicitou ao bibliotecário W.H. Williams o desenvolvimento de uma classificação para documentos desta organização (CHATFIELD, 1950, p. 263), a qual foi 
publicada em 1902, sendo baseada no método de Dewey. No ano seguinte, a empresa do ramo de energia elétrica, The General Electric Company, influenciada por adaptação semelhante do Departamento de Engenharia Mecânica da University of Illinois, publicou o Relative Index: An Extension of the Dewey System for the Electrical Industry, que relacionava assuntos sobre a produção de energia elétrica com a notação decimal. Posteriormente, em 1908, a empresa provedora de linhas telefônicas, Telephone and Telegraph Company, solicitou ao bibliotecário William $\mathrm{C}$. Bamburgh a produção de um esquema de classificação de documentos, o que originou a publicação Decimal Classification for Filing Telephone Correspondence, que largamente influenciou outras empresas do ramo a adotarem a metodologia (DEUTRICH, 1965, p. 203).

Dado o relativo sucesso inicial de tal método nestas empresas, a Commission on Economy and Efficiency criada pelo presidente estadunidense William Howard Taft ${ }^{2}$, realiza um estudo sobre em 1911, e recomenda a apropriação da classificação decimal por assuntos para a organização dos documentos nos escritórios por toda a Administração Pública daquele país (DEUTRICH, 1965, p. 204), gerando diferentes reações entre os órgãos, já que muitos deles utilizavam métodos diferentes (DEUTRICH, 1965, p. 205-208).

Os objetivos desejados para a classificação dos documentos à época eram a construção de uma metodologia que permitisse o rompimento do requisito da localização física fixa e, ao mesmo tempo, fosse automaticamente recuperado e intuitivo (CHATFIELD, 1950); (DEUTRICH, 1965).

Por outro lado, no mesmo período, na tradição dos arquivos públicos norte-americanos foram fatos de destaque: a) através de Arnald van Laer, arquivista holandês erradicado nos Estados Unidos, aplicou-se o respeito aos fundos no arranjo dos documentos custodiados pela Divisão de Manuscritos da Biblioteca do Estado de Nova York a partir de 1899; b) Arnald van Laer e Waldo Leland integraram uma comissão para investigação sobre as melhores formas

\footnotetext{
2 Muito embora seja necessária uma análise mais aprofundada sobre as aproximações e distanciamentos, a formulação de comissões feitas com o intuito de repensar a forma de criação e arquivamento de documentos na Administração Pública não era exclusividade dos EUA na época, como nos lembra Casanova (1928, p. 135-136) sobre um processo semelhante ocorrido na Itália.
} 
de preservação dos documentos públicos na American Historical Association AHA (BARRITT, 1993, p. 47).

Contudo, como a criação do Arquivo Nacional dos Estados Unidos só ocorreria em 1934 e até então inexistia um órgão que centralizasse as discussões sobre temáticas arquivísticas, ainda não era sistematicamente posto em pauta que os documentos criados nos órgãos públicos (records) comporiam os arquivos (archives). Ocorria ainda, a disputa no campo intelectual com a tradição dos curadores de manuscritos fortemente influenciada pela Biblioteconomia, que fez com que os avanços teóricos não se direcionassem sobre a classificação de documentos de arquivo no momento de sua produção (EVANS, 1966).

\section{ANÁLISE DOS INSTRUMENTOS DE CLASSIFICAÇÃO DO DEPARTMENT OF STATE (EUA) E DA SECRETARIA DE INDUSTRIA, COMERCIO E TRABAJO (MÉXICO)}

Os instrumentos para a classificação de documentos de arquivo propostos por Luis Vargas Guzmán, arquivista-chefe da Seção de Arquivo Geral do Departamento de Petroleo da Secretaria de Industria, Comercio e Trabajo do México, em seu Manual de Carteconomía (1922), fez parte de um movimento de adoção da metodologia de classificação por assuntos com notação decimal que se iniciou junto a apropriação norte americana e durou até a década de 1960 (DÍAZ AROCHE, 1972, p. 33). Além desta, destacamos outras obras que também recomendam essa metodologia: 1) Archivos: classificación decimal de los assuntos publicada pela Secretaría de Gobernación em 1919; 2) Manual de Organización de Archivos: como hay que proceder para formarlos en cada departamento administrativo; como, cuando se organicen, puede utilizarse la clasificación decimal, por Ezequiel A. Chavez em 1920 (GROSSMAN, 1958, p. 164) e; 3) Classificación decimal oficinesca de los assuntos de la Secretaría, de Francisco A. Flores em 1923 (DÍAZ AROCHE, 1972, p. 33).

Contudo, para este trabalho optamos em analisar a obra de Vargas Guzmán, uma vez que almeja o desenvolvimento não só de um instrumento de 
classificação para seu próprio órgão, como também para outros da administração pública do seu país, o que, consequentemente, permite-nos obter conclusões mais abrangentes sobre a aplicação da metodologia neste país.

Observaremos criticamente, também, o instrumento desenvolvido pelo Department of State dos Estados Unidos no seu aspecto geral (DEPARTMENT OF STATE, 1912), mas mais especificamente o recorte relacionado aos assuntos internos do Brasil. Este plano vigorou de 1910 até 1929 e mais recentemente foi publicado pelo National Archives and Records Service (1972) no período da gestão de James Rhoads, preparada por Ralph E. Russ, que reproduz alguns documentos daquele órgão junto com o plano de classificação.

A metodologia de classificação por assuntos e com notação decimal vigorou no Department of State até 1963 e incluía classificação cruzada com o objetivo de recuperar fisicamente os documentos (NATIONAL..., 1972, p. 2).

Nossa análise acerca do instrumento deste órgão público estadunidense, por sua vez, se justifica pois foi um dos primeiros a compor uma adaptação da classificação decimal por assuntos a partir do critério geográfico (CHATFIELD, 1950, p. 263). Seu plano de classificação era destinado para a correspondência e foi elaborado por seu Bureau of Indexes and Archives em 1910, sendo modificado algumas vezes durante seu período de vigência sem, entretanto, executar nenhuma transformação significativa do ponto de vista metodológico (DEPARTMENT..., 1912).

Vargas Guzmán (1922, p. 18-26), na introdução de sua obra, pontua aspectos gerais para contextualiza-la, dentre os quais destacamos: a) a definição de carteconomia no sentido etimológico e conceitual como sendo "[...]a arte de arranjar, administrar e conservar os arquivos" (VARGAS GUZMÁN, 1922, p. 18, tradução nossa); b) que uma boa organização do arquivo está associada à classificação dos documentos (VARGAS GUZMÁN, 1922, p. 20); c) a estrutura organizacional não é um parâmetro estável para classificação (VARGAS GUZMÁN, 1922, p. 21); d) que mesmo inadequada a classificação é permanente (VARGAS GUZMÁN, 1922, p. 21); e) a melhor forma de testar a capacidade de um sistema de arquivamento é solicitando que pessoas sem conhecimento do órgão ou sua rotina localizem documentos por ele (VARGAS GUZMÁN, 1922, p. 
23), e, por fim, conclui dizendo "O cérebro de toda atividade é o arquivo e por isso deve-se organizá-lo da melhor maneira possível" (VARGAS GUZMÁN, 1922, p. 26 tradução nossa).

Posteriormente o autor apresenta o funcionamento do plano de classificação criado, ressaltando a adaptação do método decimal por assuntos de Dewey. Nesse sentido, são as classes gerais:

0 - Assuntos gerais; 1- Assuntos administrativos; 2Explorações; 3- Perfuração de poços; 4-Transporte de petróleo; 5-Armazenamento de petróleo; 6-Refinação de petróleo; 7Obras complementares; 8-Estatística; 9-Publicações e assuntos de biblioteca (VARGAS GUZMÁN, 1922, p.28, tradução nossa).

Depois dessas dez classes iniciais, cada uma se desdobra em mais dez e assim sucessivamente. Utilizemos como exemplo a classe geral " 0 - Assuntos gerais":

\section{Quadro 1 - Assuntos gerais}

\begin{tabular}{|c|l|}
\hline Código & \multicolumn{1}{|c|}{ Assunto } \\
\hline 000 & Generalidades \\
\hline 001 & Faturas e listas de correspondência \\
\hline 001.1 & Recebidas \\
\hline 001.2 & Despachados \\
\hline 0001.3 & Fatura para o correio \\
\hline 0001.4 & Cadernos de entrega \\
\hline
\end{tabular}

Fonte: Vargas Guzmán (1922, p. 29, tradução nossa).

Outro exemplo da especificação a partir das classes acima é o que segue:

\section{Quadro 2 - Faturas e listas de correspondência}

\begin{tabular}{|c|l|}
\hline Código & \multicolumn{1}{c|}{ Assuntos } \\
\hline 832.20/0-49 & $\begin{array}{l}\text { Defesa do Rio de Janeiro e Bahia por redes antissubmarino e artilharia } \\
\text { costeira, 1917; instrução do Exército por oficiais militares estrangeiros; 1910- } \\
\text { 1912 e 1919; Preparação militar e fortalecimento do Exército, 1922; Redução } \\
\text { das forças militares, 1921; Tropas do estado da Bahia, 1925; Polícia militar do } \\
\text { Rio Grande do Norte e Ceará; Missões militares, 1928. }\end{array}$ \\
\hline
\end{tabular}

Fonte: Vargas Guzman (1922, p. 32, tradução nossa). 
Já o instrumento de classificação elaborado pelo Department of State tem como classes principais:

0- Geral; 1- Administração, Governo dos Estados Unidos; 2Extradição; 3- Proteção dos interesses; 4- Reivindicações; 5Congressos e Conferências internacionais. Tratados internacionais; 6- Comércio, relações comerciais; 7- Relações políticas dos Estados; 8- Assuntos internos dos Estados (DEPARTMENT..., 1912, p.III, tradução nossa.)

Normalmente classes mais específicas são sinalizadas com cruz (+) ou com asterisco $\left(^{*}\right)$. O plano ainda faz remissivas para outros códigos que indicam assuntos "semelhantes" (DEPARTMENT..., 1912, p. 30)

A expansão da última classe sobre os assuntos internos relativos ao Brasil indica também o ano e mês de vigência das classes:

\section{Quadro 3 - Assuntos militares e o Exército}

\begin{tabular}{|c|l|}
\hline Código & \multicolumn{1}{|c|}{ Assunto } \\
\hline 00 & Generalidades \\
\hline 01 & Direito, legislação e jurisprudência \\
\hline 02 & Solicitações \\
\hline 03 & Consultas, queixas e reclamações \\
\hline 04 & Traduç̃es, estudos técnicos e informes \\
\hline 05 & Desenhos, planos, cartas, fotografias \\
\hline 06 & Qualificação de franquias \\
\hline 07 & Congressos de petroleiros \\
\hline 08 & Dados geológicos, químicos, geográficos e históricos \\
\hline 09 & Cadastro \\
\hline
\end{tabular}

Fonte: National Archives and Records Service (1972, p. 7, tradução nossa).

\section{DIFUSÃO DA METODOLOGIA DE CLASSIFICAÇÃO POR ASSUNTOS NO BRASIL}

A projeção da metodologia de classificação por assuntos com notação decimal no Brasil é perceptível pelas traduções e produções sobre, como demonstra a bibliografia sobre a Administração Pública na América Latina organizada por Grossman (1958), que compreendeu as diversas dimensões do serviço público a partir das principais publicações dos países do recorte geográfico. 
No setor privado, a partir das preocupações com o valor probatório dos documentos de arquivo principalmente para fins contábeis, são produzidos manuais de classificação e arquivamento. Ernani Macedo de Carvalho, por exemplo, em seu "Manual de classificação e archivamento de papéis e documentos commerciaes e civis", publicado em 1931, assinala a:

A transformação das condições do trabalho nos escriptorios, a superabundancia de documentos escriptos impostos pelos novos methodos de conduzir negócios, a rapidez, quasi vertigem, como elles se tratam, se fazem e se desfazem, - e as próprias exigências do Codigo Commercial crearam, fatalmente, a dupla e imprescindivel obrigação de ordenar e classificar esses papeis indispensáveis ao normal e regular funcionamento das emprezas commerciaes (CARVALHO, 1931, p. 22).

Em virtude disto, a classificação é vista como lógica facilitadora da recuperação dos documentos (CARVALHO, 1931, p. 32), todavia, o autor enfoca no mobiliário como decisivo para a eficiência da classificação e arquivamento de documentos, sugerindo o uso de arquivos verticais. Adotando-se esse mobiliário, sugere-se que a composição das pastas obedeça quaisquer critérios minimamente estruturados como: o alfabético, numérico, geográfico ou decimal por assuntos (CARVALHO, 1931, p. 61).

A perspectiva de que o mobiliário é o elemento basilar na classificação e arquivamento não era exclusividade da realidade brasileira, como o arquivista do Banco de la Nación da Argentina, Eduardo Mujica Farias (1923) sugere em seu livro La Archivología Científica Moderna, pois ao divulgar o "Sistema Único Argentino", um conjunto mobiliário para arquivamento, não faz distinção dos critérios para a criação de unidades de arquivamento como Carvalho (1931).

Posteriormente, no Brasil, com a criação do Departamento Administrativo do Serviço Público - DASP (1938-1986) por Getúlio Vargas, que buscava eficiência dos procedimentos nas repartições públicas, foi necessário pensar na classificação dos documentos de arquivo nos locais de produção. Para tanto, e sendo fortemente influenciada pela difusão do método norte-americano, Maria Lourdes da Costa, chefe da Seção de Comunicação do Departamento, cujas atividades eram: "receber, registrar, distribuir, numerar, expedir e guardar a correspondência oficial e papéis relativos às atividades do DASP" (SANTOS, 2018, p. 131), visualizou a: "necessidade urgente da elaboração definitiva de um 
Código de Classificação Decimal para o arquivamento dos documentos do DASP" (SANTOS, 2018, p. 132).

Através de um dos seus veículos de informação oficial, a Revista do Serviço Público, o DASP também continuadamente veiculou artigos sobre a temática, potencializando a difusão da classificação decimal por assuntos nos órgãos públicos brasileiros. Marcílio Vaz Torres, por exemplo, publicou uma série de artigos intitulados "Apontamentos de Arquivística", desde 1953. Posteriormente Torres (1959, p. 138) defenderia o uso de um "métodos dos files", definindo como "alfabético-numérico que não segue a regra geral pois não depende do planejamento de um alfabeto fechado", cuja definição distingue os documentos produzidos nos escritórios daqueles considerados históricos e é construído a partir da noção de assunto (TORRES, 1959, p. 138).

A expansão da classificação por assunto nos órgãos produtores de documentos públicos foi constatada também por Schellenberg em sua visita ao Brasil em 1960 (SCHELLENBERG, 2015, p. 298).

Nas duas décadas seguintes à visita de Schellenberg, os arquivos e Arquivologia no Brasil passariam por grandes transformações: aprovação da criação de cursos de nível universitário; promulgação da Lei nº 6.546 de 1978, que regulamenta a profissão de arquivista; criação do Sistema Nacional de Arquivos através do Decreto $n^{\circ} 82.308$ (BRASIL, 1978), entre outros marcos de institucionalização política e científica da área.

Nesse cenário, o debate metodológico para a classificação dos documentos de arquivo ganha novas dimensões. Os estudos de Bellotto (2017, p. 347-363) adicionam uma nova perspectiva ao sugerir o uso do aporte teóricometodológico da Tipologia Documental para a identificação do tipo documental no momento de sua gênese, o que parametrizaria, por exemplo, a criação de planos de classificação funcionais. Por outro lado, parte da literatura disponível permanecia recomendando a classificação por assuntos, ainda que em grande parte reconhecessem o documento de arquivo como fruto da atividade jurídicoadministrativa (CASTRO; CASTRO; GASPARIAN, 1985, p. 100); (PAES, 1987, p. 20).

Todavia, a classificação por assuntos tem seu marco mais significativo no 
Brasil no momento de sua institucionalização pelo Conselho Nacional de Arquivos, quando da elaboração de seu instrumento de classificação relativo às atividades-meio da Administração Pública, em vigor desde 1996 e sem mudanças metodológicas desde então.

\section{CONSIDERAÇÕES FINAIS}

Como comentaram os críticos de Vargas Guzmán (1922, p. 7-17)3 no prólogo da obra que sintetiza seu instrumento de classificação, este faz uma apropriação de um sistema de notações não idealizado para arquivos e na constituição das classes por assunto, ainda que exista uma tentativa de diferenciar "assuntos" dos "acontecimentos em relação aos assuntos", ocorrem inconsistências do ponto de vista teórico-conceitual.

O instrumento do arquivista mexicano criou grupos de "generalidades" que tendem a ser usados quando se desconhece uma classe adequada para o documento a ser classificado, impedindo a materialização do relacionamento dos documentos nela classificados entre si, e até mesmo de serem recuperados para fins informacionais.

Na mesma direção vai o instrumento do Department of State, que já nas classes mais abrangentes apresentou redundâncias, e, nas classes mais específicas, concebemos a ideia de que os assuntos foram aglutinados em classes na medida em que surgiam, tornando ainda mais complexa sua notação e a idealização de um pressuposto conceitual para sua manutenção.

O produto da combinação de um sistema notacional limitado e equivocadamente fundamentado não demorou a ser percebido, como sugere o teórico de Administração Pública, Earl Latham (1943, p. 106, tradução nossa), ao se referir sobre a necessidade de buscar documentos sobre as mudanças administrativas ocorridas na I Guerra Mundial, que: "[...] eram incompletos, não cobriam os problemas correntes, relatavam fatos históricos inadequadamente ou foram impropriamente classificados".

${ }^{3}$ A obra de Vargas Guzmán é introduzida pelas análises críticas de Ezequiel A. Chavez, Atenógenes Santa Maria e Juan B. Iguíniz. 
Posteriormente, começa a ser inserida no debate arquivístico a relevância da perspectiva funcional para a classificação enquanto corolário de aplicação do princípio da proveniência. No âmbito da tradição dos arquivos públicos, Edward Campbell (1941, p. 431-432) comenta que o arranjo dos documentos de arquivo, de acordo com suas respectivas unidades produtoras, embora teoricamente adequado, demandaria um trabalho de pesquisa que talvez dificultasse o acesso ao conjunto orgânico. Nesse sentido, "para cada função haverá um ou mais tipos de documentos e todos tipos de documentos irão ter sido usados na execução de uma ou mais funções" (CAMPBELL, 1941, p. 439, tradução nossa). Já Helen L. Chatfield (1940), arquivista do Treasury Department, parte de uma abordagem semelhante e identifica a estrutura organizacional como instrumento de performance das funções específicas do produtor de documentos (CHATFIELD, 1940, p. 99). O redirecionamento teórico fundamentado na função, depois de alguns anos, faria muitos órgãos públicos nos EUA produzirem novos instrumentos de classificação (DEUTRICH, 1965, p. 218-219).

A classificação de documentos de arquivo baseada em assuntos, então surge nos Estados Unidos no fim do século XIX, a partir da urgência de algum parâmetro organização nos documentos de empresas privadas, tendo seu primeiro marco de institucionalização a partir da recomendação de seu uso na administração pública pela Comissão Taft. Posteriormente é propagada internacionalmente através de adaptação feita pelo Instituto Bibliográfico Internacional, e, nesse período, há uma maior valorização do mobiliário de arquivo em detrimento da atividade que os documentos de arquivos registram.

Transpassando as questões que a literatura sobre classificação na contemporaneidade debate, a constituição de uma perspectiva histórica, internacional e comparativa é, de maneira geral, um recurso elucidativo do desenvolvimento teórico da Arquivologia, porém, mais do que isso, sob uma ótica mais específica demonstrou a pertinência da sobreposição do papel demarcador de contextos da classificação, de manutenção do vínculo arquivístico, da organicidade e da proveniência que o plano de classificação sintetiza.

Priorizar a recuperação do conteúdo dos documentos de arquivo é colocar seu valor informativo acima da natureza do documento de arquivo, que demanda 
a percepção do seu contexto de produção. Ainda que os benefícios de um modelo holístico que integre ambos sejam evidentes, o estudo das diferenças conceituais entre esses papéis atribuídos à classificação, inclusive através da história, para conhecer o produto das metodologias de abordagem ao nosso objeto científico, pode refletir na sistematização de nossos entendimentos e na dilatação da capacidade de aplicação destes.

Se aproximarmos essa reflexão em abordagens contemporâneas da classificação de documentos de arquivo, por exemplo, no caso brasileiro, percebemos que institucionalizar uma metodologia inadequada significa: 1) de uma maneira geral ignorar a construção histórico-epistemológica do saber arquivístico, e; 2) especificamente compromete de maneira estrutural desde a produção até a avaliação, a transparência ativa dos atos e o acesso às informações contidas nos documentos públicos.

\section{REFERÊNCIAS}

BARRITT, M. R. Coming to America: Dutch archivistiek and american archival practice. Archival Issues, v. 18, n. 1, p. 43-54, 1993. Disponível em: https://minds.wisconsin.edu/handle/1793/45661. Acesso em: 11 fev. 2019

BRASIL. Resolução n. 4, de 28 de março de 1996, Brasília: Conselho Nacional de Arquivos, 29 de março de 1996.

BRASIL. Decreto ${ }^{\circ} 82.308$, de 25 de setembro de 1978. Institui o Sistema Nacional de Arquivos - SINAR. Disponível em:

http://conarq.arquivonacional.gov.br/o-sinar.html. Acesso em: 11 fev. 2019.

BRASIL. Lei $n^{\circ} 6.546$ de 4 de julho de 1978. Dispõe sobre a regulamentação das profissões de Arquivista e de Técnico de Arquivo, e dá outras providências. Disponível em: http://www.planalto.gov.br/ccivil_03/leis/1970-1979/L6546.htm. Acesso em: 11 fev. 2019.

BELLOTTO, H. L. Arquivo: estudos e reflexões. Belo Horizonte. Editora UFMG, 2017.

CAMPBELL, E. G. Functional classification of archival material. The Library Quarterly. v. 11, n. 4, p. 431-441, october, 1941. Disponível em: https://www.journals.uchicago.edu/doi/abs/10.1086/615060. Acesso em: $11 \mathrm{fev}$. 2019. 
CARAVACA, M. M. Elements and Relationships within a records classification scheme. JLIS.it., v. 8, n. 2, p. 18-33, may, 2017. Disponível em: https://www.jlis.it/article/view/12374. Acesso em: 11 fev. 2019.

CARVALHO, E. M. de. Manual de classificação e archivamento de papéis e documentos commerciaes e civis. São Paulo: Editora Itda, 1931.

CASANOVA, E. Archivistica. 2 ed. Siena: Stab. Arti Grafiche Lazzeri, 1928. Disponível em:

http://www.icar.beniculturali.it/biblio/pdf/EuCa/totalCasanova.pdf. Acesso em: 11 fev. 2019.

CASTRO, A. de M. e; CASTRO, A. de M. e; GASPARIAN, D. de M. e C.. Arquivística = técnica, Arquivologia = ciência. Brasília. ABDF, 1985.

CHATFIELD, H. L. The development of record systems. The American Archivist, v. 13, n. 3, p. 259-267, july, 1950. Disponível em: https://americanarchivist.org/doi/pdf/10.17723/aarc.13.3.f31q7442x7162754. Acesso em: 11 fev. 2019.

CHATFIELD, H. L. The problem of records from the standpoint of management. The American Archivist, v. 3, n. 2, p. 93-101, april, 1940. Disponível em: https://americanarchivist.org/doi/abs/10.17723/aarc.3.2.d7683226j7167838. Acesso em: 11 fev. 2019.

COOK, T. What is past is prologue: a history of archival ideas since 1898 , and the future paradigm shift. Archivaria, v. 43, p. 17-63, spring, 1997. Disponível em: https://archivaria.ca/index.php/archivaria/article/view/12175/13184. Acesso em: 11 fev. 2019.

COX, R. J. On the Value of Archival History in the United States. Libraries \& Culture, v. 23, n. 2, p. 135-151, Spring, 1988. Disponível em:

https://www.jstor.org/stable/25542039. Acesso em: 11 fev. 2019

CRAIG, B. L. Outward visions, inward glance: archives history and professional identity. Archival Issues, v. 17, n. 2, p. 113-124, 1992. Disponível em: https://minds.wisconsin.edu/handle/1793/45641. Acesso em: 11 fev. 2019.

CUVELIER, J. La Preparation des Archivistes. In: CUVELIER, J; STAINER, L. (Org.). Congrés de Bruxelles, 1910. Actes [...]. Bruxelles. Aux siége de la comission, 1912, p. 301-306. Disponível em:

http://extranet.arch.be/congres1910/8B887_B_0301.pdf. Acesso em: 11 fev. 2019.

DEUTRICH, M. Decimal filing: its general background and an account of its rise and fall in the U.S. War Department. The American Archivist, v. 28, n. 2, p. 199-218, april, 1965. Disponível em:

https://americanarchivist.org/doi/abs/10.17723/aarc.28.2.r828586524467632.

Acesso em: 11 fev. 2019. 
DEPARTMENT OF STATE. Classification of correspondence, 1910.

Washington. Government Printing Office, 1912. Disponível em:

https://babel.hathitrust.org/cgi/pt?id=hvd.32044097047757\&view=1up\&seq=9.

Acesso em: 11 fev. 2019.

DEVRIESE, D. Pour une archivistique scientifique: relire Muller, Feith et Fruin. COMMA, Liverpool University Press, v. 2007, n. 1-2, p. 1-11, 2007. Disponível em:

https://online.liverpooluniversitypress.co.uk/doi/abs/10.3828/comma.2007.1-

2.12?mobileUi=0\&. Acesso em: 20 dez. 2019.

DÍAZ AROCHE, C. Bibliografia sobre Archivonomia. Bibliotecas y archivos E.N.B.A., S.v., n. 3, p. 13-46, 1972. Disponível em:

http://132.248.9.34/hevila/BibliotecasyarchivosMexicoDF/1981/no12/8.pdf.

Acesso em: 11 fev. 2019.

EVANS, F. B. Modern Methods of Arrangement of Archives in the United

States. The American Archivist, v. 29, n. 2, p. 241-263, april 1966. Disponível em: https://americanarchivist.org/doi/pdf/10.17723/aarc.29.2.7j27/2p346860442. Acesso em: 11 fev. 2019.

FOSCARINI, F. Functional-based classification systems: an exploratory study of records management practices in central banks. 2009. 349 f. Phd Thesis (Doctor Of Philosophy) - Library, Archival and Information Studies Course, University Of British Columbia, Vancouver, 2009. Disponível em: http://citeseerx.ist.psu.edu/viewdoc/download?doi=10.1.1.466.3868\&rep=rep1\&t ype=pdf. Acesso em: 11 fev. 2019.

GROSSMAN, Jorge (Org.). Bibliography on Public Administration in Latin America. Washington D.C. Department of Cultural Affair - Pan American Union, 1958.

GUERCIO, M. La classificazione nell'organizzazione dei sistemi documentari digitali: criticità e nuove prospettive. JLIS. it, v. 8, n. 2, p. 4-17, may, 2017. Disponível em: https://dialnet.unirioja.es/servlet/articulo?codigo=6085170. Acesso em: 11 fev. 2019.

HENTTONEN, P.; KETTUNEN, K. Functional classification of records and organisational structure. Records Management Journal, v. 21, n. 2, p. 86-103, 2011. Disponível em:

https://www.emerald.com/insight/content/doi/10.1108/09565691111152035/full/ html. Acesso em 11 fev. 2019.

HEREDIA HERERA, A. La Archivística a debate. Boletín de la ANABAD, v. LXII, n. 1, p. 1-15, enero-marzo, 2012. Disponível em: https://revistas.unc.edu.ar/index.php/anuario/article/view/12484/13052. Acesso em: 20 dez. 2019. 
HICKERSON, T. Ten challenges for the archival profession. The American Archivist, v. 64, Spring/Summer, p. 6-16, 2001. Disponível em: https://americanarchivist.org/doi/abs/10.17723/aarc.64.1.0rg6525nu1437v31. Acesso em: 11 fev. 2019.

KETELAAR, E. The difference best postponed? Cultures and comparative archival Science. Archivaria, Canadá, v. 44, p. 142-148, 1997. Disponível em: https://archivaria.ca/index.php/archivaria/article/view/12201. Acesso em: $11 \mathrm{fev}$. 2019.

LATHAM, Earl. The Technique of Administrative Reporting. Public Administration Review, v.3, n.2, p.106-118, Spring, 1943.

LOPES, L. C. Vers une archivistique internationale à l'ère de l'information.

Archives, v. 29, n. 2, p. 45-64, 1997-1998. Disponível em: http://www.archivistes.qc.ca/revuearchives/vol29_2/29-2-lopes.pdf. Acesso em: 11 fev. 2019.

MUJICA FARIAS, E. La Archivología Científica Moderna. Buenos Aires: Banco de la Nación Argentina, 1923.

MOKHTAR, U. A.; YUSOF, Z. M. Classification: the understudied concept. International Journal of Information Management, v.35, n. 2, p. 176-182, 2015a. Disponível em:

https://ukm.pure.elsevier.com/en/publications/classification-the-understudiedconcept. Acesso em: 11 fev. 2019.

MOKHTAR, U. A.; YUSOF, Z. The requirement for developing functional records classification. International Journal of Information Management, $v$. 35, n. 4, p. 403-407, 2015b. Disponível em:

https://www.researchgate.net/publication/276159231_The_requirement_for_dev eloping_functional_records_classification. Acesso em: 11 fev. 2019.

MOKHTAR, U. A.; YUSOF, Z. Records management practice: the issues and models for classification. International Journal of Information Management, v. 36, n. 6, p 1265-1273, 2016. Disponível em:

https://www.sciencedirect.com/science/article/pii/S026840121630514X. Acesso em: 11 fev. 2019.

MOKHTAR, U. A.; YUSOF, Z. M.; AHMAD, K.; JAMBARI, D. I. Development of function-based classification model for electronic records. International Journal of Information Management, v. 36, n. 8, p. 626-634, 2016. Disponível em: https://daneshyari.com/article/preview/1025490.pdf. Acesso em: 11 fev. 2019.

NATIONAL ARCHIVES AND RECORDS SERVICE. Records of the Department of State Relating to Internal Affairs of Brazil 1910-1929. Washington: NARS, 1972. 
ORR, S. Functional-based classification of records: is it functional? 2005.

$170 \mathrm{f}$. MA Thesis (Master of Science in Records Management Course),

Northumbria Uni-versity, Newcastle, 2005. Disponível em:

https://www.researchgate.net/publication/228787956_Functions-

based_classification_of_records_is_it_functional. Acesso em: 11 fev. 2019.

PAES, M. L. Arquivos correntes, o calcanhar de Aquiles da arquivologia. Rio de Janeiro, Acervo, v. 2, n. 1, p. 17-21, jan.-jun., 1987. Disponível em:

http://www.arquivonacional.gov.br/media/v.2,n.1,jan-jun,1987.pdf. Acesso em: 11 fev. 2019.

SANTOS, P. R. E. A institucionalização da arquivologia no Brasil e a reforma administrativa no primeiro governo Vargas (1935-1945). Revista Brasileira de História, v. 38, n. 78, p. 121-146, 2018. Disponível em:

http://www.scielo.br/scielo.php?script=sci_abstract\&pid=S0102-

$01882018000200121 \&$ Ing=en\&nrm=iso\&tlng=pt. Acesso em: 11 fev. 2019.

SCHELLENBERG, T. R. Problemas arquivísticos do governo brasileiro.

Acervo, v. 28, n. 2, jul.-dez., p. 287-300, 2015. Disponível em:

http://www.brapci.inf.br/index.php/res/v/107990. Acesso em: 11 fev. 2019.

TORRES, M. V. Apontamentos de arquivística. Revista do Serviço Público, v. 84, n. 2, p. 138-144, agosto, 1959. Disponível em:

https://revista.enap.gov.br/index.php/RSP/article/view/3741. Acesso em: 11 fev. 2019.

VARGAS GUZMÁN, L. Manual de carteconomía. Cidade do México, Talleres Gráficos de la Nación, 1922.

\title{
THE "SUBJECT" AS ELEMENT FOR RECORDS CLASSIFICATION IN THE EARLY XX CENTURY AND ITS INFLUENCES ON CONTEMPORARY APPROACHES
}

\begin{abstract}
Introduction: Despite the specificities that records have, yet it is seen discussions and practices that agreed with subject-based classification. In this way is possible to reflect about this approach with a sampling that consists in two record classification plans from the early XX century, from public agencies from USA and Mexico and exposing the historical basis from part of the development of this approach in Brazil. Objectives: Firstly, it highlights the relevance of research about the history of Archival Science with an international and comparative approach. After that, it is exposed some discussions about records classification, its purposes and methods, in addition to the analysis the records classification plans and their elements, correlating them to some issues that urged from the contemporary debate of records classification. Methodology: To accomplish those objectives it was did a literature review and a systematization of Brazilian and international literature, adopting an historical gaze upon the time since 1912 until 2018. Results: The results suggests an historical perception about the need
\end{abstract}


to methodological reformulation for develop records classification plans that could properly identify the context of production of records. Conclusion: It was possible to conclude that regardless that perception, the effective diffusion of proper records classification methodologies, including in Brazil, finds an obstacle as exists an historical process not only adherence, but also mainly an institutionalization of subject-based records classification.

Descriptors: Archival Science. Public Archives. Records Classification. Records classification plan.

\title{
EL "ASUNTO" COMO ELEMENTO DE CLASIFICACIÓN DE DOCUMENTOS DE ARCHIVO EN LOS INICIOS DEL SIGLO XX Y SUS INFLUENCIAS EN ENFOQUES CONTEMPORÁNEOS
}

\begin{abstract}
RESUMEN
Introducción: A pesar de las especificidades inherentes de los documentos de archivo, encontramos discusiones y prácticas favorables para la clasificación de estos documentos basando-se en el "asunto". En este sentido, es posible reflexionar sobre este enfoque de clasificación a partir de un muestreo que consiste en dos instrumentos de clasificación de agencias públicas de principios del siglo XX en los Estados Unidos y México, así como exponer la base histórica de parte del desarrollo de esta perspectiva en el Brasil. Objetivos: En primer lugar, la importancia de los estudios sobre la historia de la archivología se enfatiza dentro de un enfoque internacional y comparativo. Por lo tanto, buscamos aclarar las discusiones sobre la clasificación de los documentos de archivo, sus objetivos y métodos, y analizar estos instrumentos de acuerdo con sus elementos de elaboración, correlacionándolos con algunas preguntas planteadas en el debate actual sobre la clasificación de archivos. Metodología: para lograr estos objetivos, utilizamos una revisión y sistematización de la literatura brasileña e internacional en perspectiva histórica, que abarcó el período de 1912 a 2018. Resultados: Los resultados sugieren una percepción histórica de la necesidad de una reformulación metodológica para la construcción de herramientas de clasificación con énfasis en identificar el contexto de producción de documentos de archivo. Conclusiones: fue posible concluir que, a pesar de esta percepción, la difusión efectiva de metodologías de clasificación adecuadas para documentos de archivo, incluido Brasil, encontró obstáculo en un proceso histórico no solo de adhesión, sino sobre todo de institucionalización de la clasificación basada en asuntos.
\end{abstract}

Palabras clave: Archivología. Archivos públicos Clasificación Plan de clasificación de documentos. 